\title{
Potencialidades de las aguas termales COMO TURISMO ALTERNATIVO EN EL ECUADOR
}

\author{
POTENTIALS OF THERMAL WATERS AS ALTERNATIVE TOURISM IN ECUADOR
}

$\mathrm{PhD}$. Edesmin Wilfrido Palacios Paredes Universidad Central del Ecuador. wilfrido.palacios@gmail.com,wpalacios@gmail.com.

PhD. Yailen Busto Yera Universidad Israel

Katherine Espinosa Estudiante Administración Turística y Hotelera, Universidad Tecnológica Israel.

Fecha de recepción: 10/04/2015

Fecha de aceptación: 24/05/2015

\begin{abstract}
Resumen
El presente artículo tiene como objetivo incentivar el desarrollo turístico del Ecuador, destacando sus riquezas naturales, potenciando especialmente el empleo de las aguas termales. Las fuentes termales emergentes del suelo, en las disímiles zonas ecuatorianas se han convertido en una alternativa saludable de turismo alternativo. La propuesta de impulsar un turismo sobre la base de explorar y aplicar todas las potencialidades de las diversas fuentes de aguas termales del Ecuador, representaría no solo beneficios por el disfrute, descanso, relajación y mejora en la salud de las personas, sino que sería factible y sustentable para el desarrollo turístico y económico del país.
\end{abstract}

Palabras clave: Aguas termales, propiedades curativas, desarrollo turístico, turismo alternativo 


\begin{abstract}
This article aims to encourage tourism development of Ecuador highlighting its natural resources, including strengthening the use of the hot springs. Emerging soil in dissimilar areas Ecuadorian hot springs have become a healthy alternative tourism. The proposal to promote tourism based on exploring and applying the full potential of the various hot springs of Ecuador, represent not only benefits for the enjoyment, resting, relaxation and improved health of individuals but would be feasible and sustainable tourism and economic development of the country.
\end{abstract}

Keywords: Hot springs, healing properties, touristic development, alternative tourism 


\section{Introducción}

"El turismo no es sólo un acto de comercio, sino que se ha convertido en un hecho de civilización"

El turismo ha sido definido como una actividad que han venido realizando los seres humanos, desplazándose de un lugar a otro por diferentes motivos (Haulot, 1963). De igual manera, Lazary y Andrade (2010) han mencionado que esta actividad se ha realizado según las motivaciones de los individuos. Por ello, Delfigalo (1991) manifestó que los turistas se han movilizado con el fin de satisfacer sus necesidades de ocio y relax. El Ecuador, a fin de adaptarse a las nuevas tendencias del turismo mundial, enfocadas al desarrollo de un turismo verde, ecológico, naturista y alternativo, ha tomado como referencia al turismo de aguas termales (Eljuri, 2004; Paguay, 2007). A más de un siglo, el investigador Wolf (1892) habría ponderado la basta riqueza del Ecuador en aguas termales y minerales. Según ha manifestado Halberstadt (1997), el Ecuador, ha sido uno de los destinos turísticos preferidos por excelencia para aquellos viajantes motivados en la búsqueda de la relajación física y espiritual con tratamientos naturales y spas.

Según Cáceres (2002), las aguas termales son consideradas una alternativa de salud, que se ha enfocado mayoritariamente a aquellas personas que prefieren una recuperación natural de sus dolencias mediante el disfrute de atractivos lugares con climas libres de contaminación y ecosistemas naturales. Por ello ha afirmado, que turismo de salud, solo podrá ser considerado aquel que logre de manera natural un ambiente adecuado para recuperar la fuerza y la salud física de los viajantes.

El agua mineralizada y caliente de las "termas" tiene diferentes efectos en el cuerpo humano. Algunos autores (Eljuri, 2012) dividen los beneficios de las aguas termales en tres: biológicos, físicos y químicos, aunque en realidad todos actúan al mismo tiempo.

El baño en aguas termales aumenta la temperatura del cuerpo, matando gérmenes, entre ellos virus, además aumenta la presión hidrostática del cuerpo, por lo que aumenta la circulación sanguínea y la oxigenación. Este aumento en la temperatura ayuda a disolver y eliminar las toxinas del cuerpo (Paz et al., 2015).

Cuando una persona se expone a un baño termal, recibe la acción directa de la temperatura de las aguas termales en forma de shock, y los minerales comienzan a ser absorbidos en pequeñas concentraciones por la piel. 
Una vez en el organismo, los minerales son depositados en el tejido celular subcutáneo, y desde ahí ejercen su acción activando el metabolismo orgánico a través del eje hipotálamo suprarrenal (Eljuri, 2012).

Teniendo como precedente los beneficios antes mencionados del empleo de las aguas termales, y de los estudios desarrollados por los investigadores citados, la presente investigación tiene como objetivo principal incentivar mediante la recopilación de información las potencialidades invaluables de desarrollar un turismo termal en el Ecuador.

Por lo antes mencionado, la investigación se enfocará en un estudio de campo realizado en los distintos atractivos naturales en donde se han identificado estas fuentes minerales. Esto permitirá diagnosticar de manera tangible la situación turística actual en cada sitio, y con ello identificar los lugares turísticos con más potencialidades en cada una de las zonas del país: una vez diagnosticadas e identificadas las áreas de aguas termales más factibles del país, impulsando el desarrollo de un Turismo Termal Alternativo. Es por ello que el presente artículo tiene como premisa lograr un incentivo a nivel local, regional y nacional hacia el desarrollo del turismo de aguas termales en el Ecuador.

\section{Desarrollo}

Según ha mencionado Cibeira (2000), su hallazgo de las aguas termales se ha considerado como un acontecimiento social debido a que ha atraído a una gran cantidad de turistas, y esto a su vez, ha dado lugar a la aparición de las denominadas "termas terapéuticas". Como han argumentado los investigadores Carrera y

Figura 1: Imágenes de las termas de Papallacta
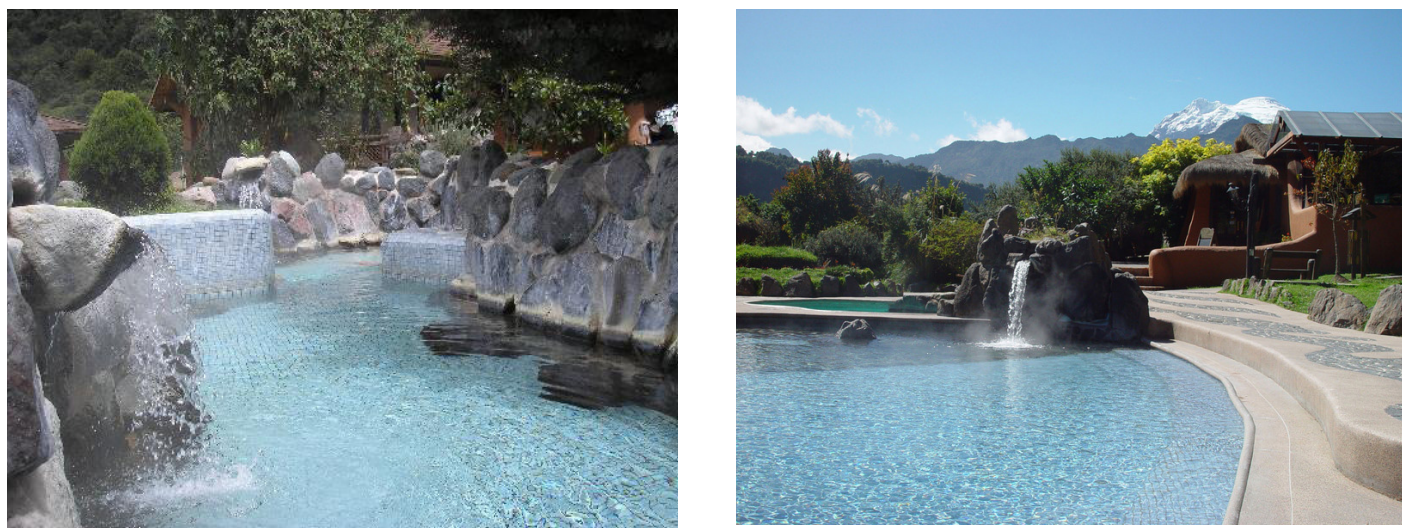

Fuente: tomadas de: www.google.com 
Lainez (2002), las termas terapéuticas han sido utilizadas para mejorar la calidad de vida de las personas, en la búsqueda de bienestar físico y mental. Dichas termas en la actualidad han sido catalogadas como centros de salud natural donde se aprovechan al máximo lascaracterísticas ambientales y cualidades mineromedicinales de estas aguas para el tratado de dolencias (Paz et al., 2015).

El experto en turismo Briceño (2004) ha mencionado que la más grande y majestuosa mega diversidad del planeta tiene su lugar en Ecuador, considerado el centro del mundo no solo geográficamente sino por su clima variado e impresionantes paisajes. De igual manera, ha denotado que el Turismo en el Ecuador tiene la esencia latina que se ha fusionado, creando así destinos inolvidables y únicos que se completan al ser adornados por sus aguas termales.

Según han mencionado Carrera y Lainez (2002), el turismo termal ha adquirido una mayor relevancia en los últimos tiempos, logrando destacarse como una de las mejores alternativas de turismo de salud. Debido a esto, Agishi (2005) ha investigado sobre los múltiples beneficios que su uso ha traído en la salud humana. Entre las principales ventajas, el autor plantea la capacidad que tienen las termas de intervenir en los procesos relajación de las personas, aumentando su ritmo cardíaco y, por ende, mejorando su circulación.

Según Verhagen et al. (2008), especialistas en medicina alternativa, las principales propiedades curativas de las aguas termales son las siguientes:

- Mejoran la alimentación de los tejidos del cuerpo en general, motivo por el cual aumenta el metabolismo.

- Estimulan las defensas del organismo.

- Depuran la sangre, eliminándose las toxinas y productos de desechos por la sudoración y diuresis que provocan.

- Estimulan las secreciones del tracto digestivo y del hígado, ayudando así a la digestión.

- Reactivan el metabolismo retardado en muchos reumáticos.

- Tienen poder desestabilizante sumamente útil, considerando la participación alérgica en el orden de las afecciones reumáticas.

- Reeducan el sistema termorregulador, de enorme importancia en el reumático que ha perdido su capacidad de reaccionar y adaptarse a los cambios del medio ambiente.

- Tienen un elevado poder analgésico y calmante de dolores.

- Relajan los músculos y por su acción revulsiva y resolutiva, actúan sobre los edemas, tumefacciones y procesos crónicos fibrosos.

- Sedan el sistema nervioso, siendo un sedante y relajante, ideal para el stress y el ritmo de vida actual.

- Reconstituyen y tonifican la piel.

- Ejercen acción relajante sobre las contracturas y rigideces neuro-músculo-osteo-articulares.

- Tienen un marcado efecto positivo en las enfermedades crónicas de la piel y en las enfermedades respiratorias leves.

Ante todos los beneficios que las aguas termales ejercen sobre la salud de las personas (Agishi, 2005), es necesario puntualizar que en dependencia de las características químico-físicas de las mismas serán más evidentes o no sus resultados medicinales. 
Según Carrasco (2008), se pueden identificar en el Ecuador dos tipos de aguas termales, según su composición químico-física: las minerales y las sulfurosas. Por otra parte, existe otra clasificación, atendiendo a su forma de creación: las que están contenidas en piscinas naturales de tierra, como es el caso de las que originalmente descubrieron y usaron los indígenas de la región, y las que son encausadas hacia piscinas artificiales, hechas por el hombre (Paz et al., 2015).

Investigaciones desarrolladas por Mukdise (2013) demuestran que los niveles y tipos de minerales así como grados de temperatura del agua en las termas varían según dónde se localicen. Las temperaturas de las aguas subterráneas pueden estar determinadas por su nivel de profundidad y por los movimientos de las placas tectónicas que inducen mayor o menor calor en dichas aguas subterráneas.

Toda la región ubicada al norte de Riobamba en la Sierra ecuatoriana, produce aguas termales espectaculares debido a la presión que sobre estas ejercen varios volcanes que existen en la región, entre los que se encuentra el volcán activo más alto del país, el Cotopaxi (Hopey, 2012).

En los pueblos de Baños y Papallacta existen muchos de estos manantiales que al combinarse con la presencia de una exuberante vegetación, dada su cercanía con el Oriente, convierten a la región en un verdadero paraíso de aguas termales donde abundan spas y sitios turísticos de gran calidad (González, 2010).

Figura 2: Imágenes de las termas de Baños
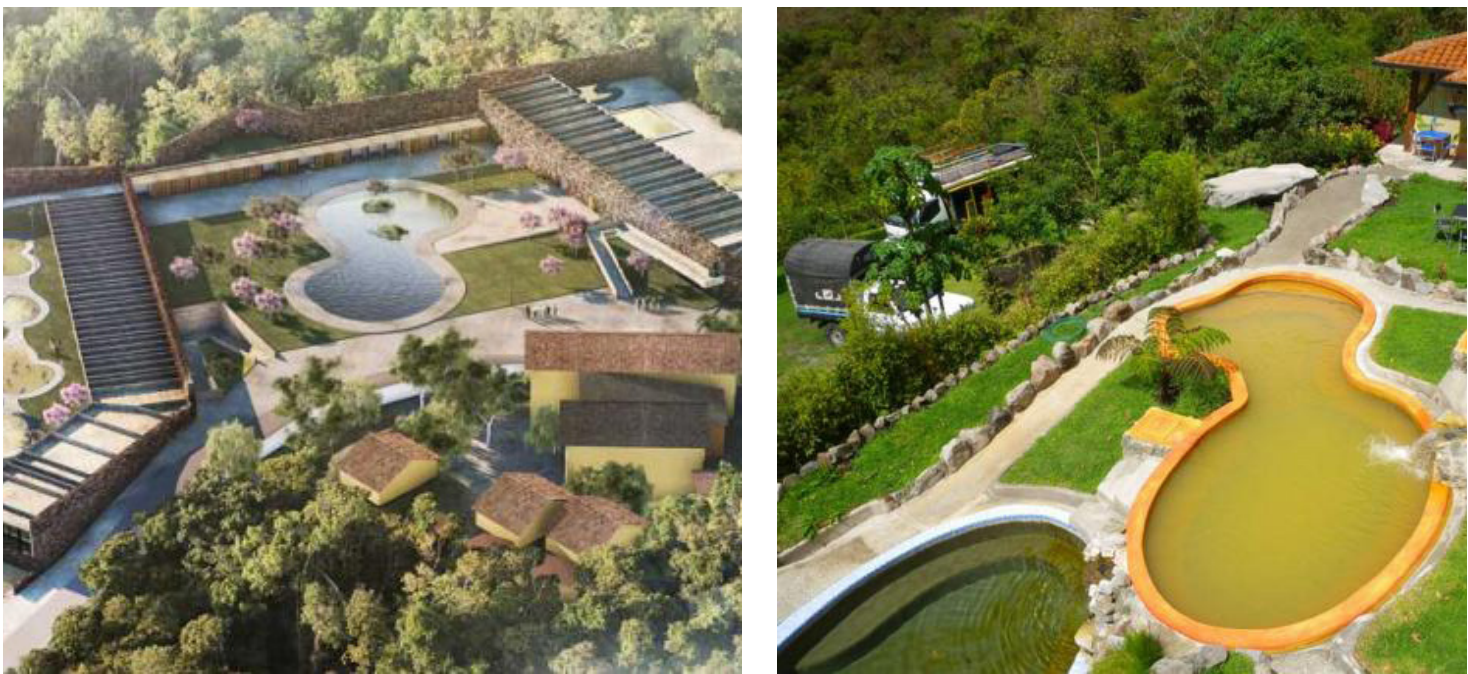

Fuente: tomadas de: www.google.com 
No obstante a los notables beneficios de estas aguas, se hace necesario mencionar algunas recomendaciones o aspectos importantes para su adecuado uso. Al respecto, Méndez (2010) menciona que al poseer estos baños de aguas termales una temperatura elevada, se debe tener un período de tres a cuatro semanas para volver a realizar un baño termal, de esta manera el organismo de las personas puede nuevamente normalizarse.

Como se ha evidenciado hasta este punto en la investigación, son disímiles los aspectos positivos desde el punto de vista medicinal que se le atribuye al uso de las aguas termales. Por otra parte, en cuanto a las ventajas económicas para el desarrollo turístico del país, Jordán (2012) ha considerado al turismo de aguas termales como una potente fuente de ingresos económicos, siendo extremadamente beneficiadas las comunidades en donde se encuentran enmarcadas.

El Plan Estratégico de Desarrollo de Turismo Sostenible para el Ecuador (PLANDETUR, 2013) diseñado por el Ministerio de Turismo del país, en su proyección para el año 2020 ha planteado convertir el TURISMO DE TERMAS en una de las principales fuentes de ingresos para el país.

Es por ello que el Ministerio de Turismo del Ecuador (MINTUR, 2014) se ha trazado como objetivos impulsar y fortalecer el desarrollo económico-social de todas las comunidades que se encuentran enmarcadas en estos atractivos.

A pesar de que en la actualidad se vislumbra un apoyo por parte del gobierno y el Ministerio de Turismo, algunos especialistas en el área insisten en la necesidad de buscar proyectos concretos que impulsen el incremento y a su vez el mejoramiento de los lugares que ofrecen este tipo de alternativa para la relajación de las personas (turismo alternativo de termas).

\section{Conclusiones}

La presente investigación sintetiza los principales beneficios que ofrece para la sa- lud de las personas el empleo de las Aguas Termales o Terapéuticas. Por otra parte, se constata que a pesar de que existen en todo el Ecuador termas potenciales bien definidas (Termas de Baños, Termas de Papallacta, etc.), aún existen áreas en las cuales el desarrollo de un turismo alternativo basado en el adecuado aprovechamiento de estos recursos naturales es muy incipiente o deficiente.

El desarrollo de un Turismo Termal no solo proporcionará ventajas desde el punto de vista medicinal para las personas, sino también desde el punto de vista económico-social para la comunidad donde se enmarque.

Finalmente, se evidencia que aunque exista a nivel de ministerio y de país la intención y proyección de potenciar este tipo de turismo alternativo, es sin dudas menester de los investigadores, académicos, estudiantes y comunidad en general llevarlo a hechos. 


\section{Bibliografía}

Agishi, Y. (2005). Las aguas termales y sus propiedades curativas. Accesible en: http:// www.geosalud.com/aguas_termales/aguas_ termales.htm

Briceño, J. (2004). All you need is Ecuador. Accesible en: http://ecuador.travel/ es?cat=49/es/es/es/es/en

Cáceres, R. (2002). Turismo Ecológico y de Salud. Accesible en: http://www.tsaitami. com/Tours.aspx?id=32

Carrasco, M. (2008). Baños de agua santa. Accesible en: http://banosaguasantamoca.blogspot.com/

Carrera, V., y Lainez A. (2002). Análisis y plan de marketing para redefinir el manejo del complejo termal turístico Telesforo Vi- llacres L.- "Baños Termales San Vicente". Accesible en: http://www.cib.espol.edu.ec/digipath/d_tesis_pdf/d-31095.pdf

Cibeira, R. (2000). Aguas termales, cura termal. Accesible en: http://www.geosalud. com/aguas_termales/curatermal.htm

Delfigalo, L. (1991). Motivación y satisfacción turística. Accesible en: http://www.youblisher.com/p/187557-Motivacion-y-satisfaccion-turistica/

Eljuri, G. (2004). El desarrollo turístico. Accesible en: http://www.explored.com.ec/noticias-ecuador/el-desarrollo-turistico-174989.html

Eljuri, G. (2012). Aguas termales atraen a los turistas de baños de Cuenca. Accesible en: http://www.explored.com.ec/noticias- ecuador/aguas-termales-atraen-a-los-turis- tas-de-banos-de-cuenca-559319.html

González, R. (2010). Proyecto de imple- mentación centro de estética y spa, Repúbli- ca Dominicana. Accesible en: http://www.monografias.com/trabajos83/primor-centro-estetica-spa/primor-centro-estetica-spa.shtml

Halberstadt, J. (1997). Aguas termales y spas en Ecuador. Accesible en: http://www.ecuadorexplorer.com/es/html/aguas-termales-yspas.html

Haulot, A. (1963). El turismo social. Accesible en: http://www.aporrea.org/actualidad/a164597.html

Hopey, M. (2012). Aguas termales y spas en el Ecuador. Accesible en: //www.ecuadorexplorer.com/es/html/aguas-termales-y-spas.html

Jordán, B. (2012). Propuesta para el desarrollo de micronegocios de turismo comunitario en la comuna baños termales de San Vicente y el Complejo "Telesforo Villacres Lainez con la participación activa de sus habitantes". Accesible en: http://repositorio.ucsg.edu.ec/ bitstream/123456789/348/1/TUCSG-PRE-ESP-AETH-64.pdf

Lazary B. y Andrade V. (2010). Experien- cia turística, ocio/recreación y mediación Un estudio del proyecto "Turismo Jovem Cidadão" en Río de Janeiro, Brasil, Estud. perspect. tur. vol.19 no.6. 
Méndez, A. (2010). Blog de ciencias médicas.com. Accesible en: http://blog.cienciasmedicas.com/archives/853

MINTUR. (2014). Turismo, servicios y direccionamientos del turismo ecuatoriano. Accesible en: http://www.servicios.turismo. gob.ec/

Mukdise, M. (2013). Nuevo turismo termal. Accesible en: http://mundodeportes. net/2014/10/24197

Paguay, J. (2007). Planificación turística en Ecuador. Accesible en: https://jorgepaguay.wordpress.com/2012/02/29/plandetur-2020/

Paz, J., Quet, J., Tenorio, I. (2015). Las aguas termales como medicina del futuro. Accesible en: http://www.geosalud.com/aguas_termales/aguas_termales.htm

PLANDETUR . (2013). Plan estratégico de desarrollo de turismo sostenible para Ecuador “PLANDETUR 2020”. Accesible en: https:// jorgepaguay.files.wordpress. com/2012/03/plandetur.pdf

Verhagen, A.P., Bierma-Zeinstra, S.M.A.,

Boers M, Cardoso, J.R., Lambeck, J. (2008). Balneoterapia para la osteoartritis. Accesible en: http://www.bibliotecacochrane.com.

Wolf, T. (1892). Geografía y Geología del Ecuador. Accesible en: http://www.cervantesvirtual.com/nd/ark:/59851/bmcd2279 
